Supplement of Geosci. Model Dev., 14, 2525-2544, 2021

https://doi.org/10.5194/gmd-14-2525-2021-supplement

(C) Author(s) 2021. CC BY 4.0 License.

(c) (i)

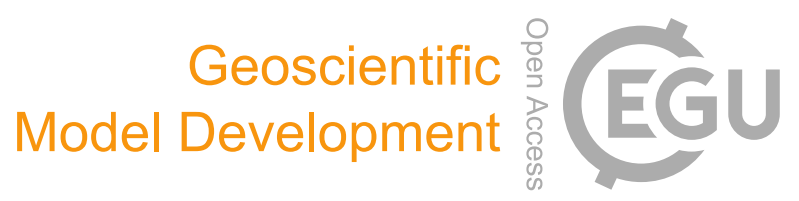

Supplement of

\title{
The Environment and Climate Change Canada Carbon Assimilation System (EC-CAS v1.0): demonstration with simulated $\mathrm{CO}$ observations
}

Vikram Khade et al.

Correspondence to: Vikram Khade (vikram.khade@canada.ca)

The copyright of individual parts of the supplement might differ from the article licence. 


\section{Section S1. The EC-CAS meteorological assimilation}

Table S1 provides details of the parameter values and their associated parameterization schemes that are involved in the generation of forecast ensemble members. Figures S1-S4 compare EC-CAS' performance for meteorological variables to that of the parent ECCC EnKF system. Figures S4-S5 show the impact of removing satellite observations on the verifications against radiosondes.

Table S1: The 64 different ensemble forecast members use different choices of model parameters associated with physical parameterization schemes. The options that can be chosen are indicated in this table. Note that the choice of convection schemes is not independently varied. Instead the choice of deep convection scheme dictates the choices of shallow convection and condensation schemes. Choice 1 includes Kain-Fritsch with Kuo-transient shallow convection and Sundqvist condensation while the other option is to use Kuo deep convection with no shallow scheme and modified Sundqvist condensation.

\begin{tabular}{|c|c|c|}
\hline Parameterization process & Options & Meaning of option \\
\hline Deep convection & $\begin{array}{ll}\text { - } & \text { Kain-Fritsch (Kain and Fritsch 1993) } \\
\text { - } & \text { Kuo (Kuo 1974; Geleyn 1985) }\end{array}$ & Flag to choose scheme \\
\hline Shallow convection & $\begin{array}{l}\text { Kuo transient (Kuo 1965; Bélair et } \\
\text { al. 2005) } \\
\text { - none }\end{array}$ & Flag to choose scheme \\
\hline Condensation & $\begin{array}{ll}\text { - } & \text { Sundqvist (Sundqvist et a. 1989) } \\
\text { - } & \text { Modified Sundqvist (Dastoor 1994) }\end{array}$ & Flag to choose scheme \\
\hline $\begin{array}{l}\text { Orographic } \\
\text { Gravity wave drag }\end{array}$ & $\begin{array}{ll}\text { - } & 0.4 \times 10^{-5} \mathrm{~m}^{-1} \\
\text { - } & 0.8 \times 10^{-5} \mathrm{~m}^{-1} \\
\text { - } & 1.2 \times 10^{-5} \mathrm{~m}^{-1}\end{array}$ & $\begin{array}{l}\text { Intensity of gravity wave drag } \\
E \mu_{\mathrm{e}} / 2 \text { (McFarlane 1987, Eq. } \\
(2.30))\end{array}$ \\
\hline $\begin{array}{l}\text { Orographic } \\
\text { Gravity wave drag }\end{array}$ & $\begin{array}{ll}- & 0.5 \\
- & 1.0 \\
- & 1.5\end{array}$ & $\begin{array}{l}\text { Minimum value of the drag } \\
\text { coefficient in the orographic } \\
\text { blocking scheme }\end{array}$ \\
\hline Boundary Layer & $\begin{array}{ll}- & 0.85 \\
- & 1.0\end{array}$ & $\begin{array}{l}\text { Parameter (turbulent Prandtl } \\
\text { number) which links stability } \\
\text { functions for temperature and } \\
\text { momentum (Charron et al. } \\
\text { 2010, section 2b) }\end{array}$ \\
\hline Surface layer & $\begin{array}{ll}\text { - } & \text { Blackadar (1962) } \\
\text { - } & \text { Bougeault-Lacarrère (1989) }\end{array}$ & Flag to choose scheme \\
\hline Surface layer & $\begin{array}{ll}\text { - } & \text { True } \\
\text { - } & \text { False }\end{array}$ & $\begin{array}{l}\text { Thermal roughness length } \\
\text { formulation over water given } \\
\text { by Eq. (3) of Deacu et al. } \\
2012\end{array}$ \\
\hline $\begin{array}{l}\text { Latent heat flux over } \\
\text { ocean }\end{array}$ & $\begin{array}{ll}\text { - } & \text { True } \\
\text { - } & \text { False }\end{array}$ & $\begin{array}{l}\text { Flag to account for ocean } \\
\text { salinity on saturation specific } \\
\text { humidity at ocean surface } \\
\text { (boundary condition for latent } \\
\text { heat flux calculation) }\end{array}$ \\
\hline
\end{tabular}



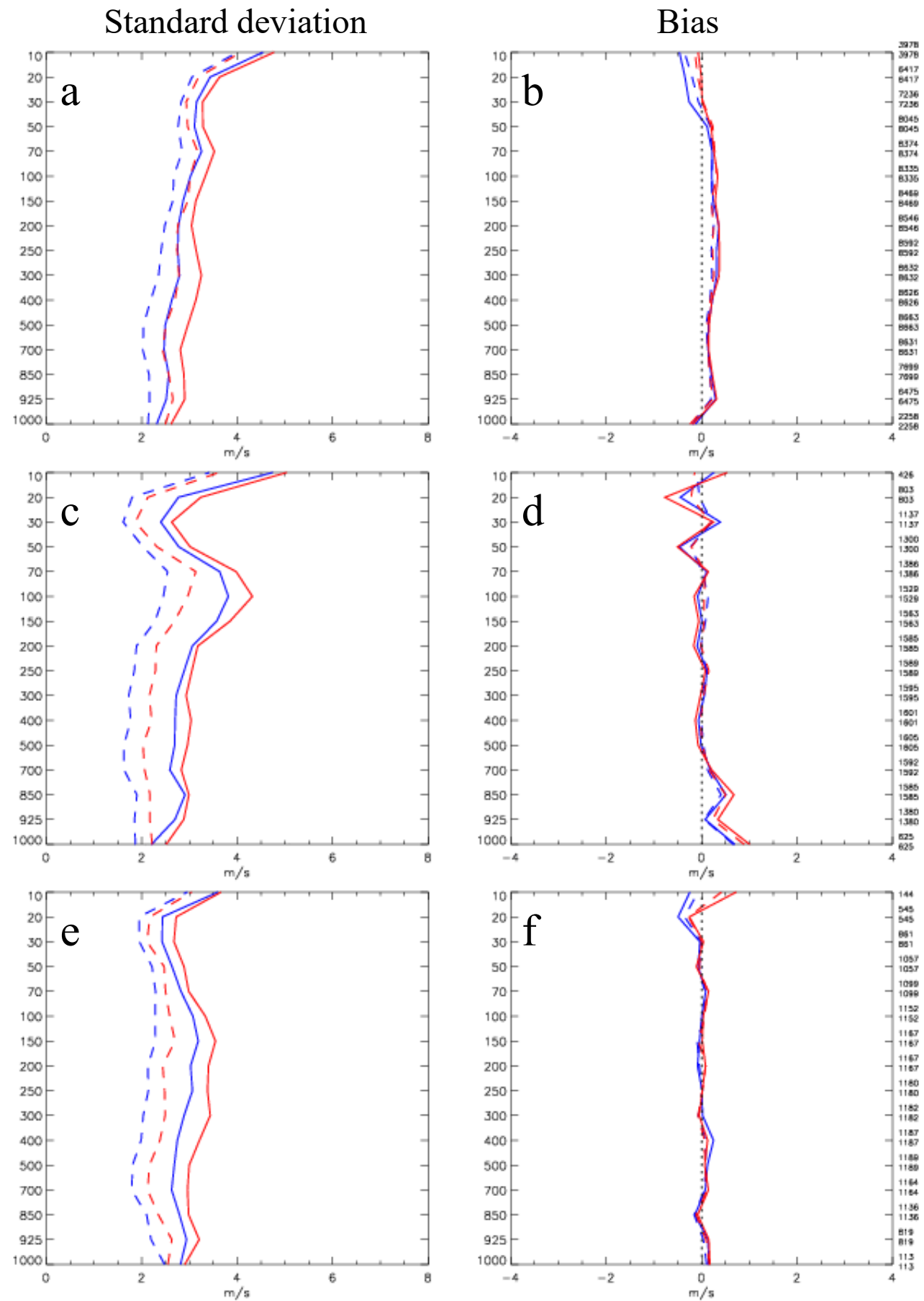

Figure S1: The impact of reducing resolution and ensemble size and removing satellite radiances in ECCAS. Statistics of differences between meteorological analyses (dashed curves) and $6 \mathrm{~h}$ forecasts (solid curves) of zonal wind (m/s) with radiosonde observations at 0 and 12 UTC for the period of 28 Dec. 2014 0 UTC to 9 Jan. 201512 UTC, inclusive. The blue curves are for the EnKF experiment from our version of the GEPS 4.1.1 code while the red curves are for the EC-CAS system. The vertical axis is pressure in $\mathrm{hPa}$. The left column shows standard deviations while the right column shows bias. The regions are: northern extratropics $\left(20^{\circ} \mathrm{N}-90^{\circ} \mathrm{N}\right)$ (panels a,b), tropics $\left(20^{\circ} \mathrm{S}-20^{\circ} \mathrm{N}\right)$ (panels c,d) and southern 
extratropics $\left(20^{\circ} \mathrm{S}-90^{\circ} \mathrm{S}\right)$ (panels e,f). The number of observations used in each statistic is shown at the right side of the right most panels.
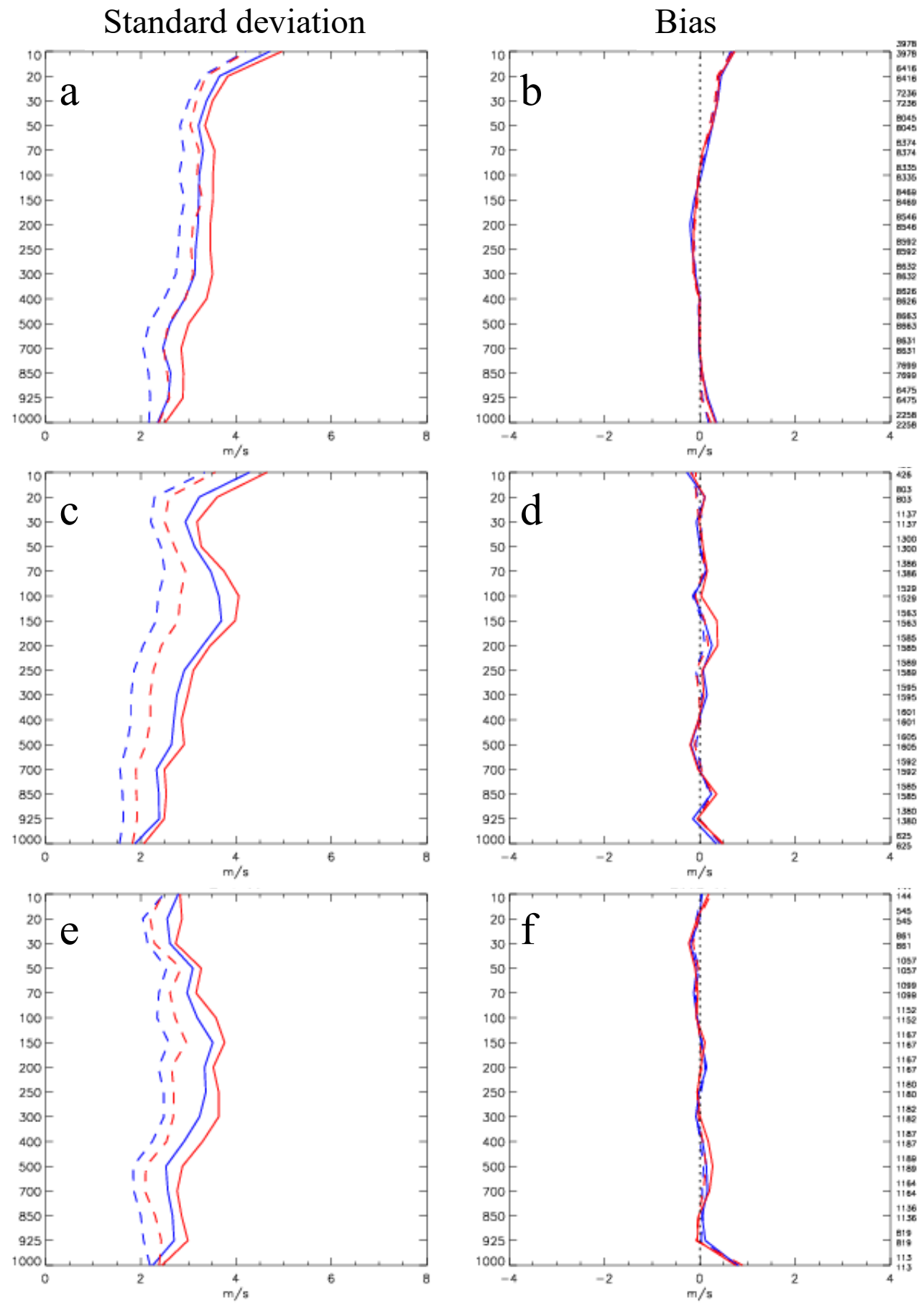

Figure S2: As in Figure S1 except for meridional wind (m/s). 

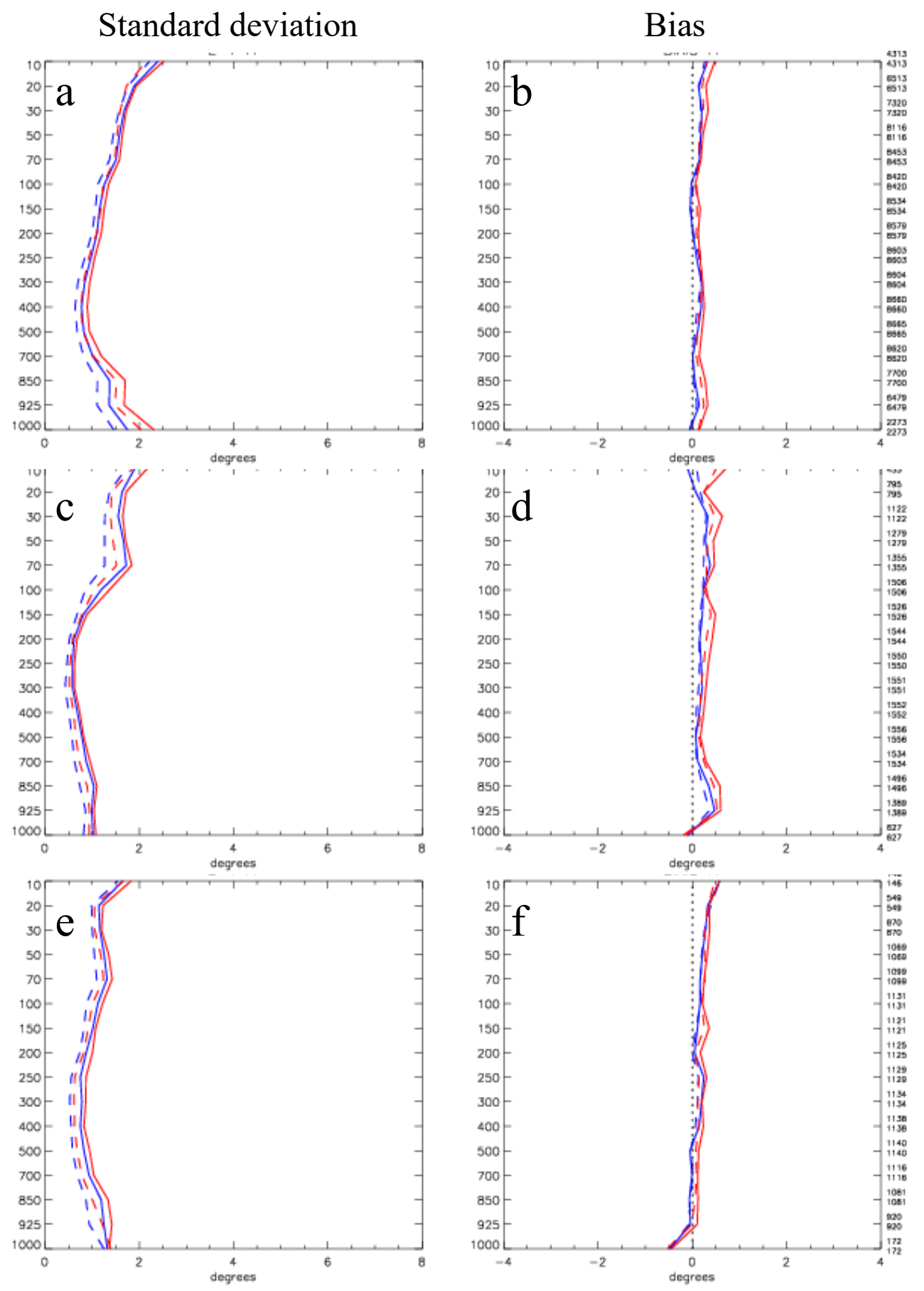

Figure S3: As in Figure S1 except for temperature (Celsius). 

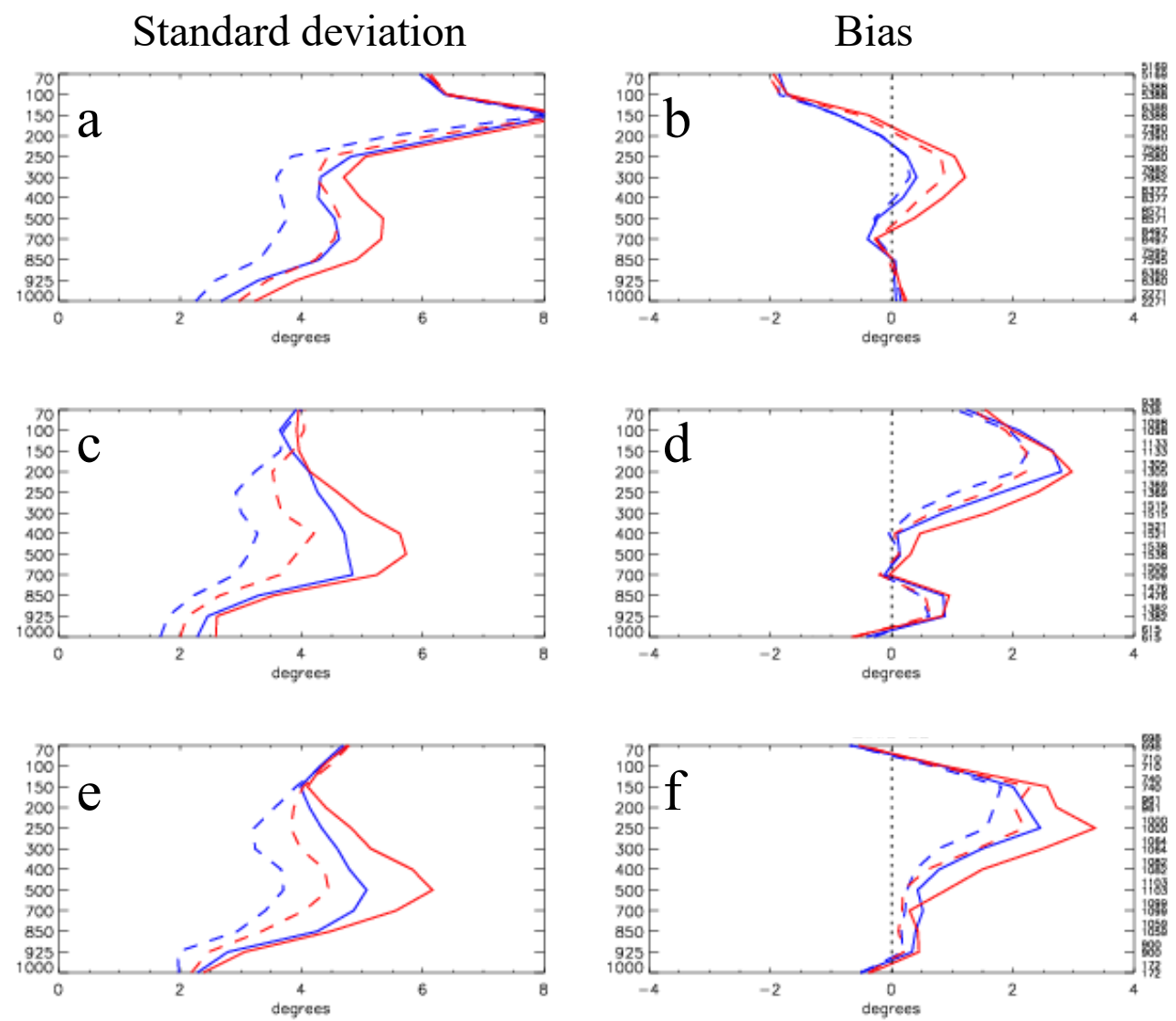

Figure S4: As in Figure S1 except for dew point depression (Celcius). 

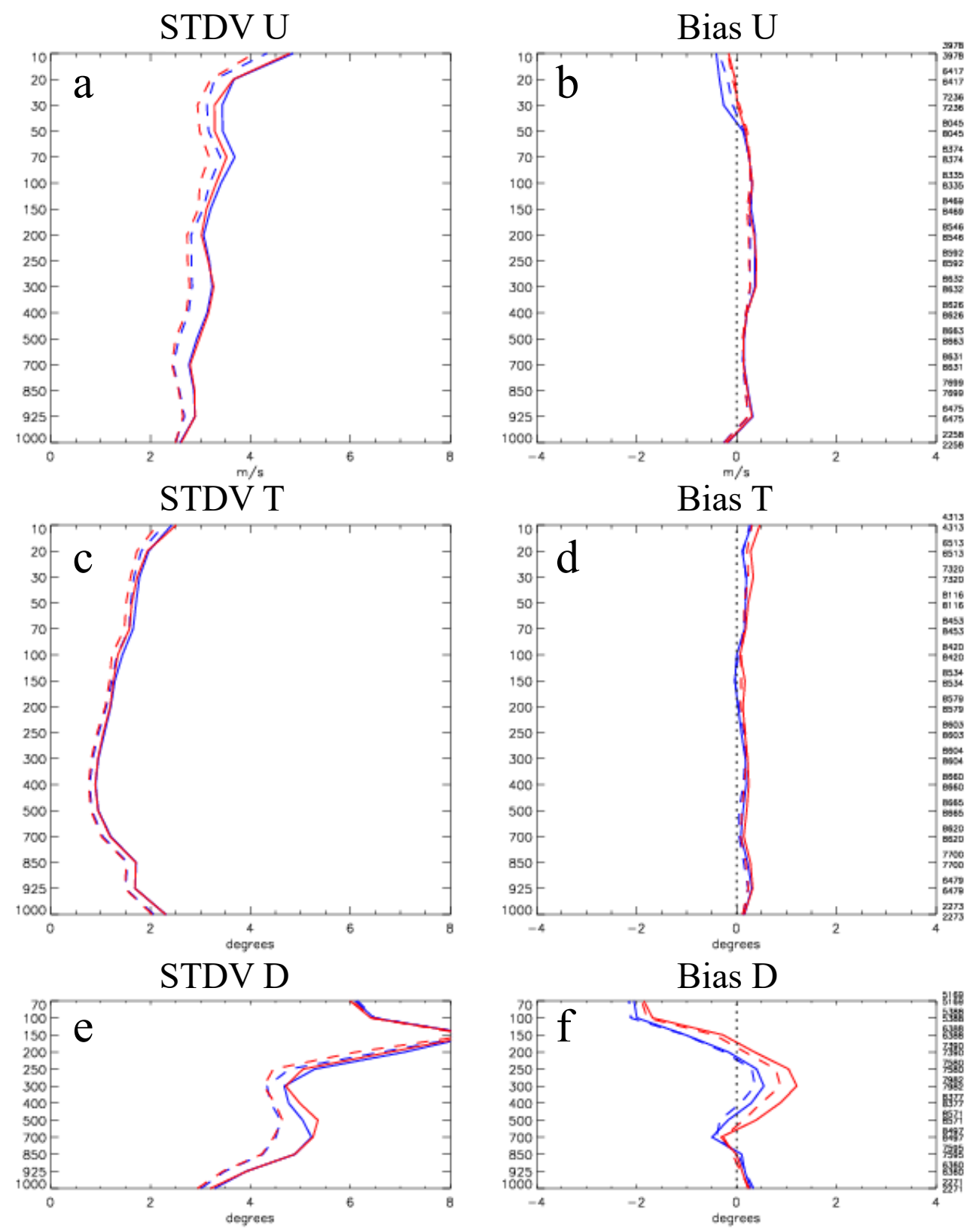

Figure S5: Impact of not assimilating satellite radiances. Statistics of differences between meteorological analyses (dashed curves) and $6 \mathrm{~h}$ forecasts (solid curves) with radiosonde observations at 0 and 12 UTC for the period of 28 Dec. 20140 UTC to 9 Jan. 201512 UTC, inclusive for the northern extratropics $\left(20^{\circ} \mathrm{N}-90^{\circ} \mathrm{N}\right)$. The EC-CAS EnKF cycles were identical except that satellite radiances were assimilated (blue curves) or were not assimilated (red curves). The variables shown are zonal wind in $\mathrm{m} / \mathrm{s}(\mathrm{a}, \mathrm{b})$, temperature in Celsius (c,d) and dewpoint depression (e,f). The vertical axis is pressure in hPa. The left column shows standard deviations while the right column shows bias. The number of observations used in each statistic is shown at the right side of the right most panels. 

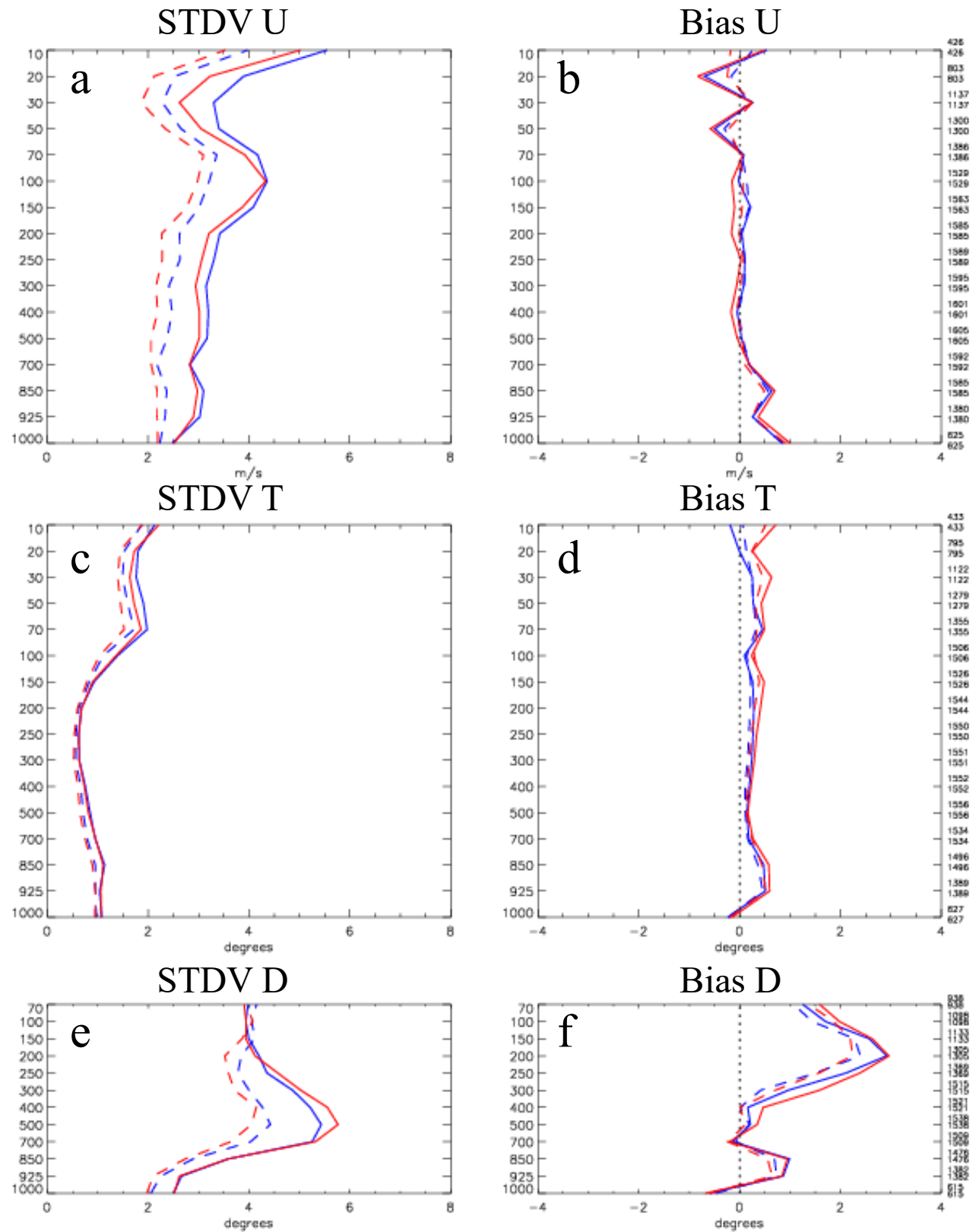

Figure S6: As in Figure S5 except for the Tropics $\left(20^{\circ} \mathrm{S}-20^{\circ} \mathrm{N}\right)$. 


\section{Section S2. Global mean computation:}

To compute the global mean quantities shown in Figures 5 and 7, model variables were integrated over the Earth's surface and normalized by the area of the sphere. The computation was discretized for a uniform latitude and longitude grid spacing. Thus, for a given quantity such as an error field, F, (e.g. ensemble mean temperature minus true temperature), the global mean is computed as follows:

$$
\bar{F}=\sum_{i, j} F_{i, j} W_{i, j}
$$

where $i$ is the latitude index from 1 to $200, \mathrm{j}$ is the longitude index from 1 to 400 and $W_{i, j}$ is a scaling factor related to grid cell surface area:

$$
\begin{aligned}
& W_{i, j}=\frac{\cos \theta_{i}}{S} \\
& S=\sum_{i, j} \cos \theta_{i}
\end{aligned}
$$

Here $\theta_{i}$ is the latitude.

\section{Section S3. Summer 2015 state estimation experiments :}

The efficacy of the HYPNET in constraining the CO state is tested for the summer of 2015. The control experiment starts on 2015061418 and ends on 2015073018. Another experiment which assimilates HYPNET is carried out over the same period. Both the experiments assimilate the same meteorological observations. The spin up for the HYPNET experiment is from 2015061418 to 2015070512. The HYPNET observations are assimilated starting on 2015070518. The HYPNET observations are assimilated for a total of 25 days. Every day has 4 assimilation cycles.

Figure S7 shows that the Canadian surface flux in July is higher than that in January. The maxima in central Africa shifts southwards in July compared to January. Comparing Figure S8 with Figure 6 in the manuscript it is clear that the RMSE over North America is higher in July. Note that the experiment results are averages over 25 days in summer while those in winter are averages over 48 days. Figure S10 compared with Figure 9(a) in the manuscript shows that the benefit during summer over North America is higher than that in winter. This demonstrates the EnKF's ability to estimate the $\mathrm{CO}$ state during active forest fires. 
Truth : 2015 Jan flux
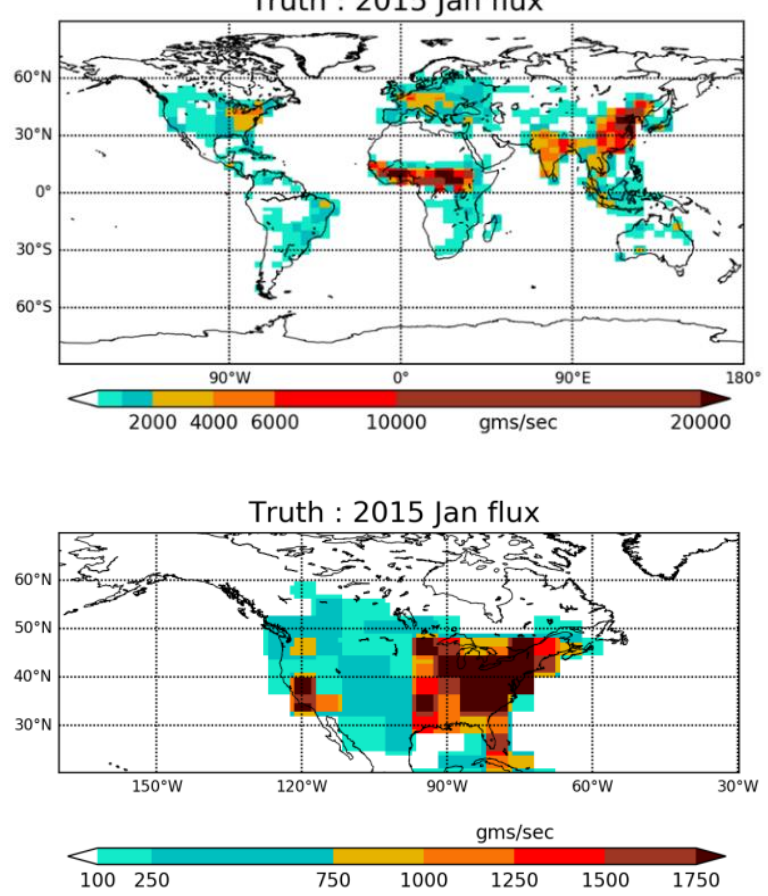

Truth : 2015 July flux

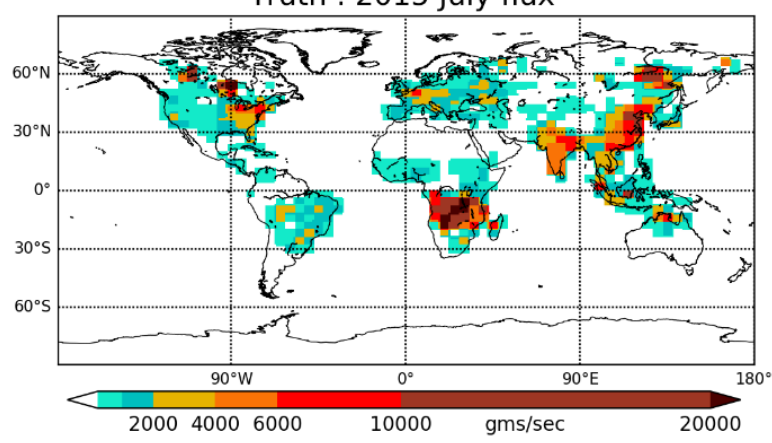

Truth : 2015 July flux

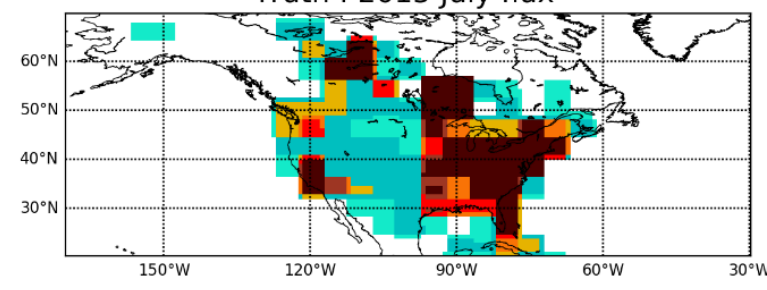

gms/sec

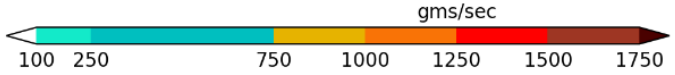

Figure S7 : Comparison between the true surface flux fields for January and June 2015. The top panels show the global distribution. The bottom panels show the same flux fields zoomed in over North America.

(a) CO column mean

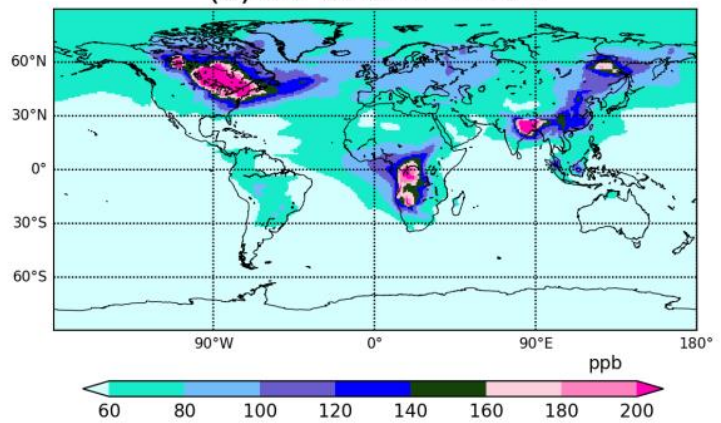

(b) CO column spread

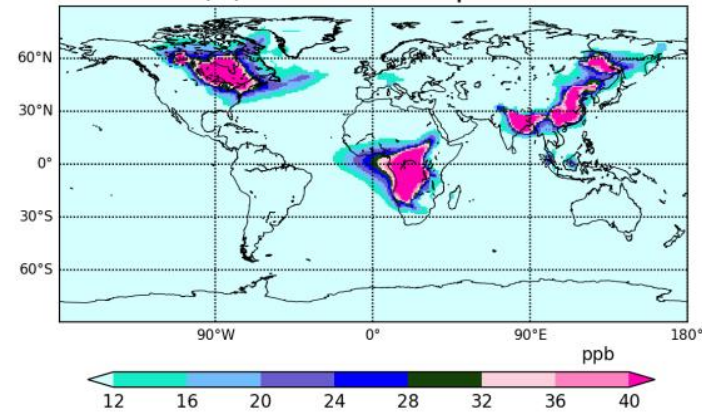


(c) RMSE (Control)

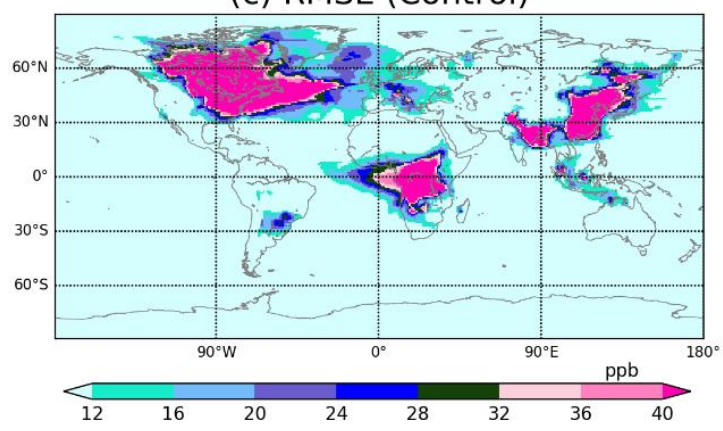

(d) RMSE (HYPNET)

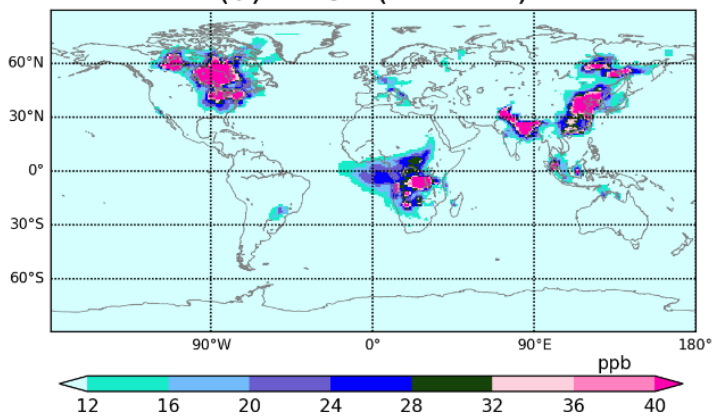

Figure S8 : In each panel, column mean (0-5 km) averages of fields from 05 July 2015 18:00:00 UTC to 30 July 2015 00:00:00 UTC are shown. (a) CO ensemble mean of control experiment. (b) CO ensemble spread of the control experiment. (c) RMSE in the control experiment. (d) RMSE of the HYPNET experiment.

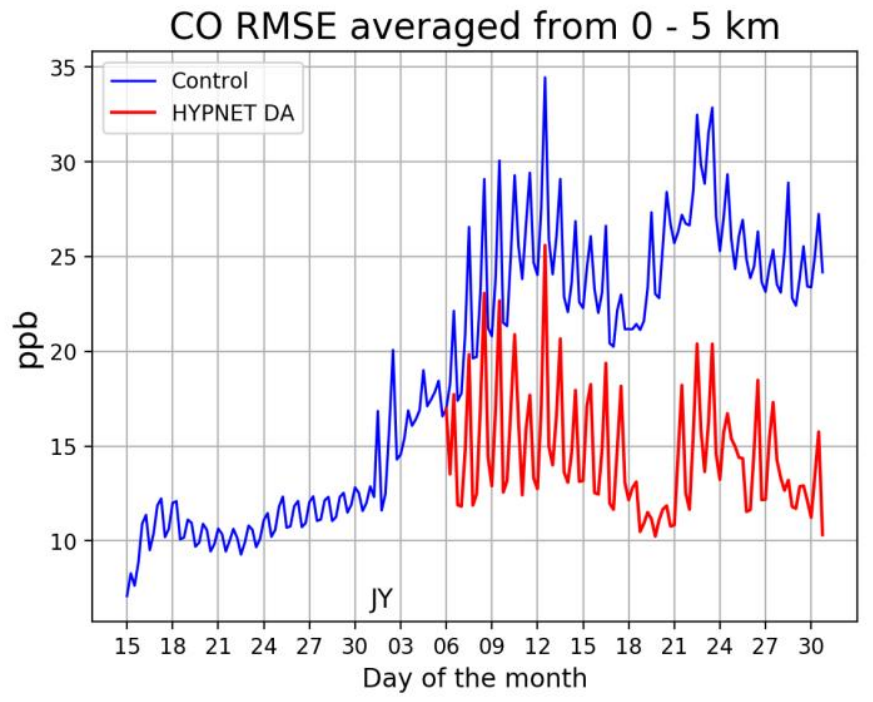

Figure S9: RMSE of the global mean, ensemble mean CO field for the control (EXP_CNTRL, blue curve) and EXP_HYP (red curve) experiments. The JY on the X-axis shows the start of July 2015. The global mean benefit is about $10 \mathrm{ppb}$. 


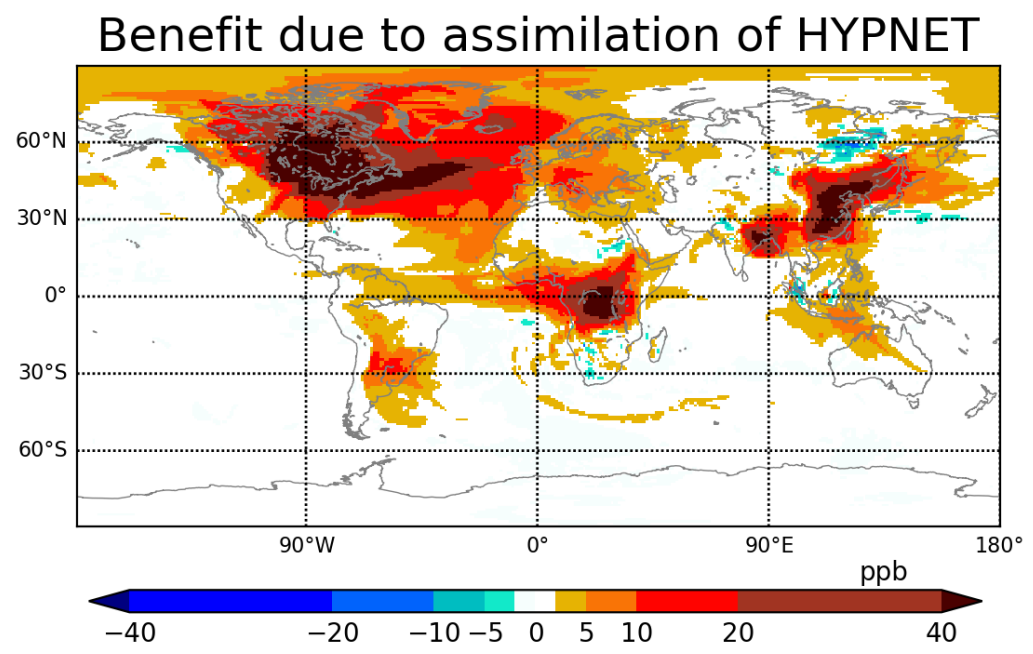

Figure S10 : The average benefit from assimilating HYPNET observations from $0-5 \mathrm{~km}$ is shown. The mean relative benefit is about $49 \%$.

\section{References :}

Bélair, S., J.Mailhot, C.Girard, and P.Vaillancourt, 2005: Boundary layer and shallow cumulus clouds in a medium-range forecast of a large-scale weather system.Mon. Wea. Rev., 133, 1938-1960.

Blackadar, A. K., 1962: The vertical distribution of wind and turbulent exchange in a neutral atmosphere.J. Geophys. Res., 67, 3095-3102.

Bougeault, P., and P.Lacarrère, 1989: Parameterization of orography-induced turbulence in a meso-betascale model. Mon. Wea. Rev., 117, 1872-1890.

Charron, M., Pellerin G., Spacek, L., Houtekamer, P.L., Gagnon, N., Mitchell, H., and L. Michelin, 2010 : Toward random sampling of model error in the Canadian Ensemble Prediciton System Monthly Weather Review 138 (5), 1877-1901.

Dastoor, A. P., 1994: Cloudiness parameterization and verification in a large-scale atmospheric model.Tellus, 46A, 615-634.

Deacu, D., Fortin, V., Klyszejko, E., Spence, C., and P. Blanken 2012 : Predicting the net Basin supply to the Great Lakes with a hydrometeorological model, 13(6), 1739-1759.

Geleyn, J-F., 1985: On a simple, parameter-free partition between moistening and precipitation in the Kuo scheme. Mon. Wea. Rev., 113, 405-407. 
Kain, J. S., and J. M.Fritsch, 1993: Convective parameterization for mesoscale models: The Kain-Fritsch scheme. The Representation of Cumulus Convection in Numerical Models, Meteor. Monogr., No. 24, Amer. Meteor. Soc., 165-170.

Kuo, H. L., 1965: On formation and intensification of tropical cyclones through latent heat release by cumulus convection. J. Atmos. Sci., 22, 40-63.

Kuo, H. L., 1974: Further studies on the parameterization of the influence of cumulus convection on large-scale flow.J. Atmos. Sci., 31, 1232-1240.

McFarlane, N. A., 1987: The effect of orographically excited gravity-wave drag on the general circulation of the lower stratosphere and troposphere. J. Atmos. Sci., 44, 1775-1800.

Sundqvist, H., E.Berge, and J. E.Kristjánsson, 1989: Condensation and cloud parameterization studies with a mesoscale numerical weather prediction model. Mon. Wea. Rev., 117, 1641-1657. 